\title{
A Long Term Review of Surgically Treated Enlarged Breasts
}

\section{Pius Agbenorku}

Reconstructive Plastic Surgery \& Burns Unit, Department of Surgery, Komfo Anokye Teaching Hospital, School of Medical Sciences, Kwame Nkrumah University of Science \& Technology, Kumasi, Ghana.

Email: pimagben@yahoo.com

Received July $4^{\text {th }}$, 2013; revised August $3^{\text {rd }}, 2013$; accepted August $11^{\text {th }}, 2013$

Copyright (C) 2013 Pius Agbenorku. This is an open access article distributed under the Creative Commons Attribution License, which permits unrestricted use, distribution, and reproduction in any medium, provided the original work is properly cited.

\begin{abstract}
Introduction: Breast hypertrophy (excessive enlargement of breast), a condition though rare, is well pronounced in some females. Surgery either by reduction mammaplasty or sub-cutaneous mastectomy is often employed in treatment of this condition. Aim: This study seeks to find out the long term level of satisfaction of the surgery on these persons after about 10 - 12 years after treatment. Materials and Methods: From January 1994 to December 2000, the Komfo Anokye Teaching Hospital (KATH) carried out surgeries on 43 females who presented with several degrees of breast hypertrophy. Patients were asked to answer questionnaires on their condition pre-operatively and post-operatively during the long term review process. Results: Thirty-four (79.1\%) patients out of the 43 were available for the review with the patients stating there was much (100\%) improvement in terms of the pain they felt in the neck, upper and lower back regions. There was no re-occurrence of the condition in any of the patients; 29 (85.3\%) stated they were satisfied and that their new breast size(s) was/were excellent for them. Conclusion: The pre-operative complications experienced by these patients were resolved hence this surgical procedure was good and the quality of life of these persons had been improved.
\end{abstract}

Keywords: Breast Hypertrophy; Reduction Mammaplasty; Sub-Cutaneous Mastectomy; Quality of Life; Satisfaction

\section{Introduction}

The breast is a sign of female sexual identity. The breasts are hemispheric and located anteriorly on the pectoralis major muscle. In the average young lady the breasts have elliptical bases located between the second and sixth ribs vertically; horizontally they lie between the midaxillary line and the lateral edge of the sternum [1]. In breastfeeding women, milk produced from the breast provides nourishment for the babies.

Breast enlargement is a normal physiological process that occurs in females; however it becomes a disorder when the breast enlargement becomes pronounced causing discomfort and hardship to persons and thus affecting their normal daily life and activities. This anomaly has been divided into three categories namely: juvenile breast hypertrophy or virginal/pubertal/juvenile macromastia, gestational macromastia (macromastia occurring during pregnancy) and macromastia in adult women with no

"Conflict of interest: The author declares that he has no conflict of interest to disclose. identifying cause.

Virginal breast hypertrophy/juvenile gigantomastia/ juvenile macromastia is the excessive enlargement of the breast tissue or diffuse enlargement of breasts in young women in early teen years. This excessive enlargement of breasts usually causes both physical and psychosocial problems [2-4] and could eventually affect their future. It usually occurs in girls between 8 to 16 years with rapid enlargement of breasts; hormonal studies in these individuals are normal [5-7]. Although it is a benign condition and may not necessarily lead to death of the individual, it causes the individual to develop negative self image and hence affects the individual's life in totality. The growth is usually bilateral though cases of unilateral hypertrophy have also been reported $[7,8]$. The aetiology of juvenile breast hypertrophy is uncertain [5-7]. Although virginal breast hypertrophy occurs sporadically, some familial cases have also been reported [5,9].

Usually the sizes of both breasts vary in a way resulting in asymmetry. Due to the nature of the breast and size, they usually find it difficult to get the right sized bra 
to fit them. Also, the weight of the breasts causes intense pain in their neck and upper region; the condition incapacitates them from partaking in some activities such as sports.

Treatment of breast hypertrophy is by surgical procedure which may be reduction mammaplasty or subcutaneous mastectomy with simultaneous or secondary breast implant placement depending on the condition. Improvements in the quality of life of persons who have undergone surgery by reduction mammaplasty have also been documented [10-12]. Accurate diagnosis is necessary before surgery; mammography is needed to exclude any underlying tumour. However, some authors require surgery be carried when the breasts have fully developed since this may result in avoidance of multiple operations $[13,14]$. Studies by Agbenorku et al. from Komfo Anokye Teaching Hospital (KATH) revealed an increase in the number of patients presenting with symptomatic macromastia in the Plastic Surgery Unit of KATH [15-17]. This study seeks to find out the long term satisfaction of these persons after surgery.

\section{Materials and Methods}

\subsection{Study Setting}

Komfo Anokye Teaching Hospital (KATH), located in Kumasi is the second-largest hospital in Ghana and the only tertiary health institution in the middle belt of the country. It is the main referral hospital for the Ashanti, Brong-Ahafo, Northern, Upper East and Upper West Regions.

\subsection{Data Collection and Analysis}

From January 1994 to December 2000 forty-three (43) females suffering from enlarged breasts (macromastia/ breast hypertrophy) presented themselves to KATH Plastic Surgery Unit where they consented to undergo surgery depending on the condition each presented. Inferior pedicle was employed in patients (20 - 39 years) who underwent reduction mammaplasty whiles nipple areolar grafts was employed in patients who underwent subcutaneous mastectomy with implants (19 years and younger).

For the review exercise the patients were contacted using the addresses given and by telephone calls. The consents of these patients were sought and they were presented with questionnaires by the assistant research officer. This review was undertaken from April 2011 through to March 2012.

Information obtained was displayed descriptively in tables using SPSS version 18.0 (SPSS, Inc., Chicago, IL, USA).

\subsection{Ethical Clearance}

Ethical Clearance was obtained from the Kwame Nkru- mah University of Science and Technology School of Medical Sciences/Komfo Anokye Teaching Hospital Committee on Human Research, Publication and Ethics, Kumasi.

\section{Results}

Reduction mammaplasty was carried out on 25 patients while subcutaneous mastectomy with simultaneous breast implant placement was carried out on 18 patients. Bilateral hypertrophy was recorded in 39 patients while unilateral cases were recorded in 4 patients. Average tissue excised from each breast was $4000 \mathrm{~g}$. Out of the 43 patients who had undergone surgery, 34 (79.1\%) were available for the review. The patients were all females with ages ranging from 10 - 39 years at the time of surgery and 20 - 49 years post-surgery (review time) (Table 1).

There was no re-occurrence of the conditions recorded after surgery during this long term review (Figures 1-5).

The pre- and post-operative conditions were displayed and listed in "Table 2".

Persons who experienced complications after surgery during the follow up were asked to grade the extent of complication as being 1-Bad, 2-Worse or 3-Worst (Table 3).

\section{Discussion}

\subsection{Physiological Complications}

Breast hypertrophy is associated with a lot of discomfort creating various inconveniences for individuals suffering from the condition. Breast reduction and subcutaneous mastectomy are some of the surgical procedures which help to alleviate these pains and discomfort.

Breast hypertrophy poses serious effects on the muscoskeletal system resulting in upper/lower back pain, shoulder pain, neck pain and shoulder grooving. From this study, pre-operatively, 30 (88.2\%) reported experiencing neck pain, all 34 (100.0\%) patients reported ex-

Table 1. Age distribution of the patients at surgery and post-surgery times (those who were available for the review).

\begin{tabular}{ccc}
\hline Pre-surgery (years) & Frequency & $\begin{array}{c}\text { Post-surgery Review } \\
\text { (years) }\end{array}$ \\
\hline $\mathbf{1 0}$ - 14 & 5 & $20-24$ \\
$\mathbf{1 5}-\mathbf{1 9}$ & 13 & $25-29$ \\
$\mathbf{2 0}-\mathbf{2 4}$ & 4 & $30-34$ \\
$\mathbf{2 5}-\mathbf{2 9}$ & 5 & $35-39$ \\
$\mathbf{3 0}-\mathbf{3 4}$ & 4 & $40-44$ \\
$\mathbf{3 5}-\mathbf{3 9}$ & 3 & $45-49$ \\
\hline
\end{tabular}




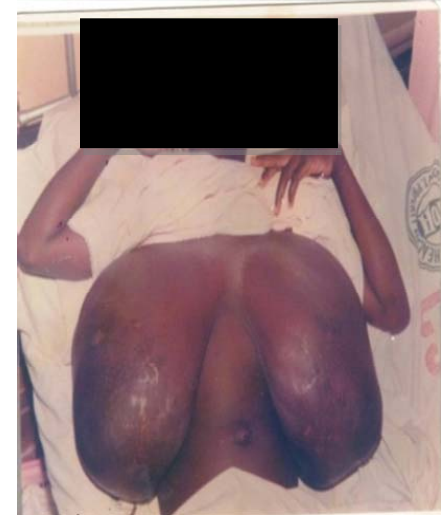

(a)

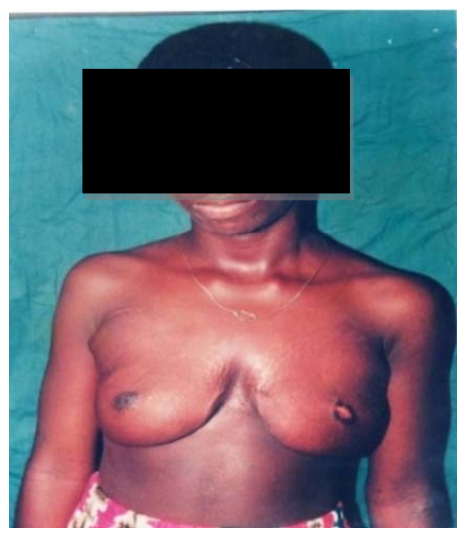

(b)

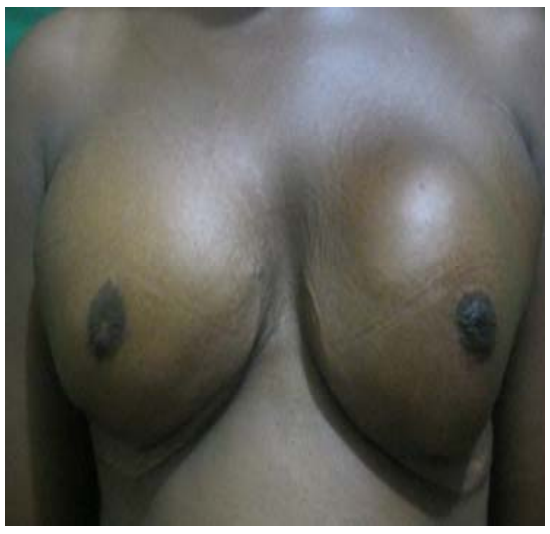

(c)

Figure 1. A 16-year-old girl: (a) Pre-surgery; (b) Immediate post-surgery; (c) Long-term post-surgery results.

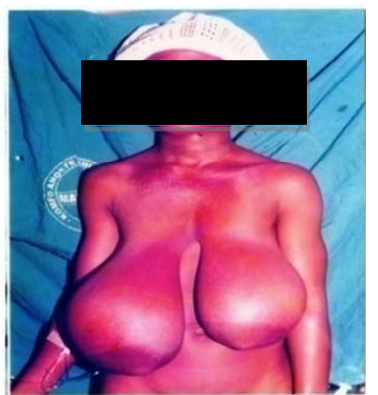

(a)

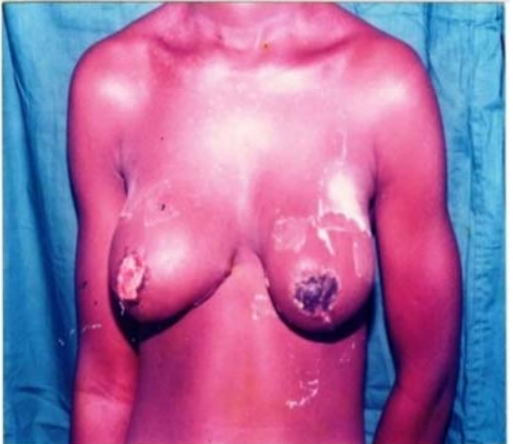

(b)

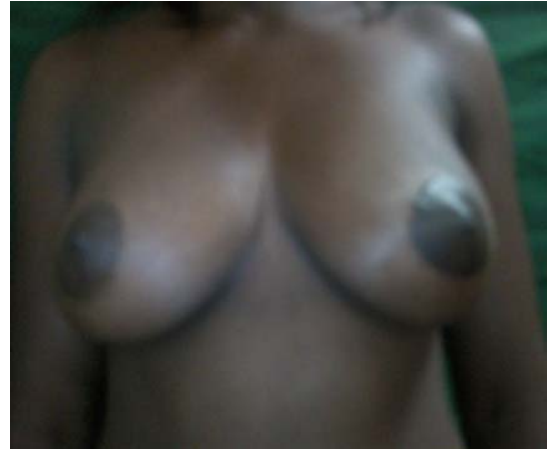

(c)

Figure 2. A 13-year-old girl: (a) Pre-surgery; (b) Immediate post-surgery; (c) Long-term post-surgery results.

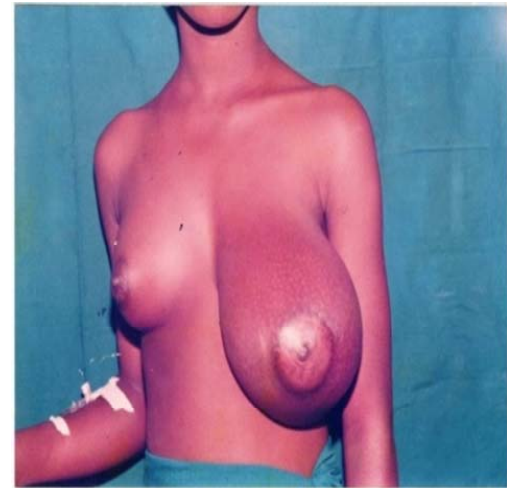

(a)

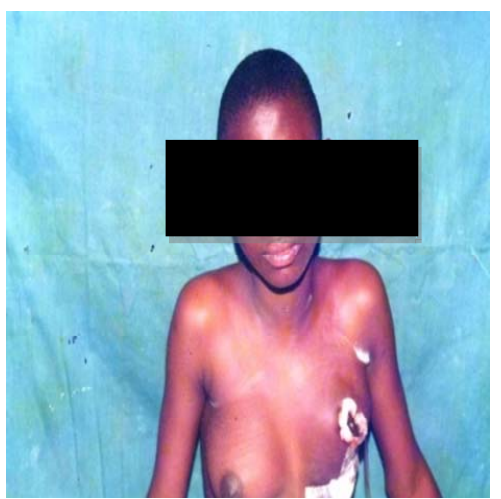

(b)

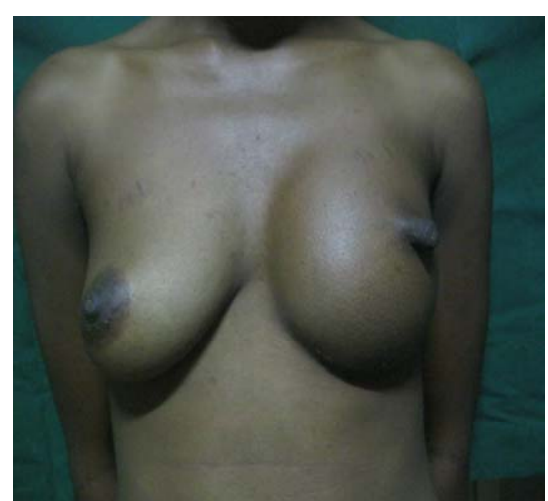

(c)

Figure 3. A 12-year-old girl: (a) Pre-surgery; (b) Immediate post-surgery; (c) Long-term post-surgery results.

periencing shoulder pain, upper/lower back pain, shoulder grooving from bra straps and breast pain. Postoperatively, the patients reported that the pains in all the areas stated above had resolved and were no longer experiencing any pain except for only one patient $(2.9 \%)$ who stated she was still experiencing some neck pain. This pain in the neck region reported by this patient might be caused by another disease or condition other than the breast pathology. Sabino (2008) stated reduction mammaplasty relieved pain in the lower back region in patients with breast hypertrophy [18]. Relief from the pre-operative complications by patients in the current study is confirmed in a similar study by Davis et al. (1995); they found out that reduction mammaplasty decreased breast size and significantly relieved pre-operative symptoms associated with mammary hypertrophy [19]. Davis et al. (1995) reported further that pre-operative complaint of shoulder grooving (94\%), shoulder 


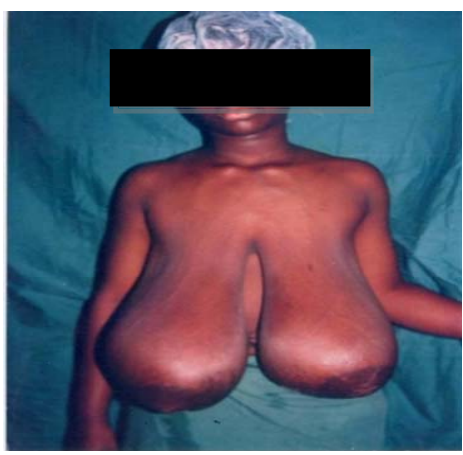

(a)

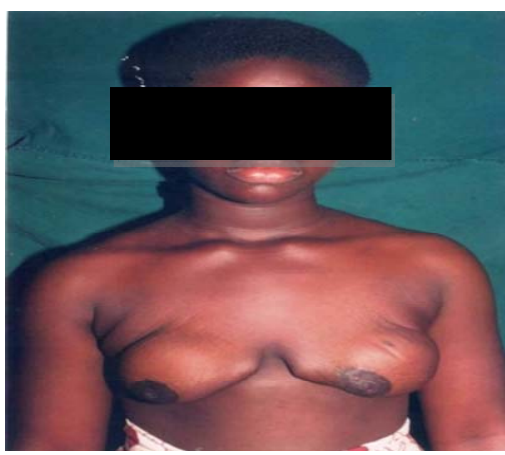

(b)

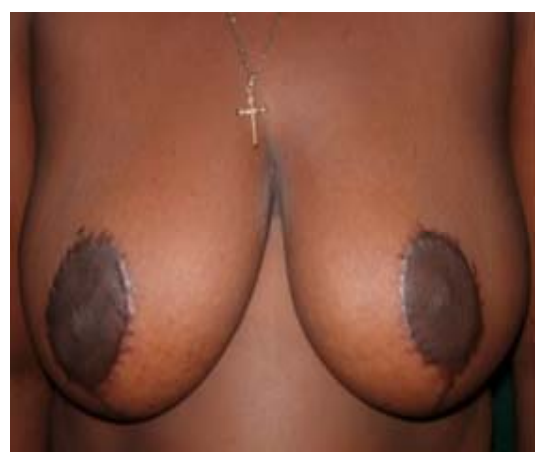

(c)

Figure 4. A 14-year-old girl: (a) Pre-surgery; (b) Immediate post-surgery; (c) Long-term post-surgery results.

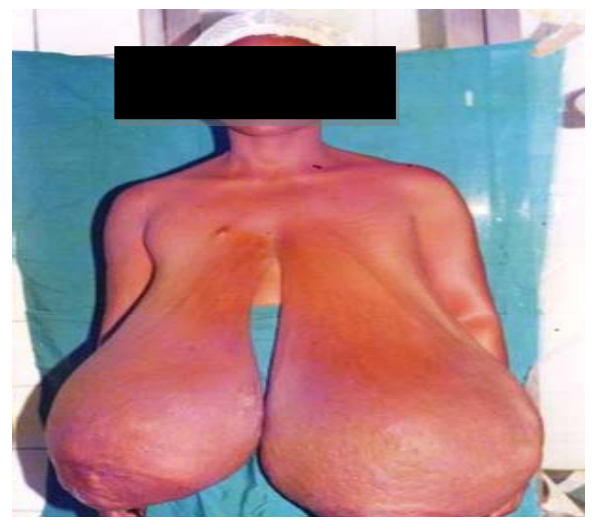

(a)

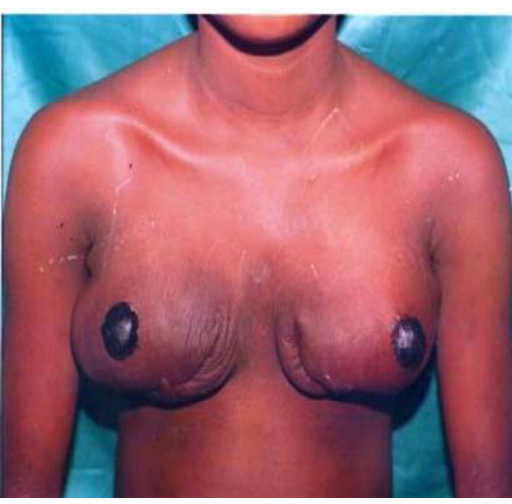

(b)

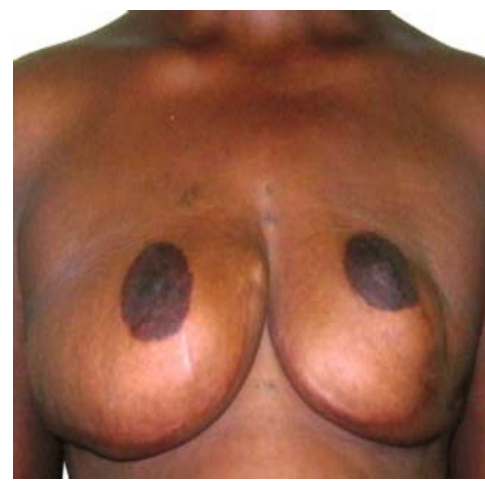

(c)

Figure 5. A 26-year-old girl: (a) Pre-surgery; (b) Immediate post-surgery; (c) Long-term post-surgery results.

Table 2. Pre- and post-operative conditions of the patients $(N=34)$.

\begin{tabular}{ccc}
\hline & Pre-operative No. of patients (percentage) & Post-operative No. of patients (percentage) \\
\hline Headache & $23(67.6)$ & $3(8.8)$ \\
Neck pain & $30(88.2)$ & $1(2.9)$ \\
Shoulder pain & $34(100.0)$ & $0(0.0)$ \\
Upper back pain & $34(100.0)$ & $0(0.0)$ \\
Lower back pain & $34(100.0)$ & $0(0.0)$ \\
Shoulder grooving & $34(100.0)$ & $0(0.0)$ \\
Pain/numbness in the finger(s) & $28(82.4)$ & $0(0.0)$ \\
Breast pains & $34(100.0)$ & $0(0.0)$ \\
Intertrigo & $30(88.2)$ & $0(0.0)$ \\
Difficulty in participating in sports & $30(88.2)$ & $0(0.0)$ \\
Difficulty finding clothes to fit & $30(88.2)$ & $0(0.0)$ \\
Teasing by people & $34(100.0)$ & $0(0.0)$ \\
Poor self image & $34(100.0)$ & $0(0.0)$ \\
Inability to breastfeed & $7(20.6)$ & $18(52.9)$ \\
Decreased milk production & $4(11.8)$ & $8(23.5)$ \\
Reduced nipple sensitivity & $0(0.0)$ & $20(58.8)$ \\
Nipple deformation & $29(85.3)$ & $16(47.1)$
\end{tabular}


Table 3. Extent of complications in the patients after surgery.

\begin{tabular}{cccc}
\hline & $\begin{array}{c}\text { Bad (1) No. of } \\
\text { patients (percentage) }\end{array}$ & $\begin{array}{c}\text { Worse (2) No. of } \\
\text { patients (percentage) }\end{array}$ & $\begin{array}{c}\text { Worst (3) No. of } \\
\text { patients (percentage) }\end{array}$ \\
\hline Inability to breastfeed & $0(0.0)$ & $0(0.0)$ & $18(52.9)$ \\
Decreased milk production & $6(17.7)$ & $2(5.9)$ & $0(0.0)$ \\
Reduced nipple sensitivity & $15(44.1)$ & $3(8.82)$ & $2(5.88)$ \\
Nipple deformation & $7(20.6)$ & $4(11.8)$ & $5(14.7)$ \\
Headache & $2(5.9)$ & $1(2.9)$ & $0(0.0)$ \\
Neck pain & $1(2.9)$ & $0(0.0)$ & $0(0.0)$ \\
\hline
\end{tabular}

pains (93\%), back pain (81\%) were significantly reduced following surgery [19]. A similar retrospective study undertaken to evaluate the long term results of reduction mammaplasty by Brühlmann and Tschopp (1998) on 114 patients who underwent an average reduction of $1266 \mathrm{~g}$ revealed $91.5 \%$ of the patients noticed a decrease in shoulder, neck and back pain and lessening of brassiere grooves [20].

From the current study, follow up revealed non-occurrence of the conditions. For 18 (52.9\%) patients who underwent sub-cutaneous mastectomy, they were in their early teens and the result from this study showed nonrecurrence of the enlarged breast condition after about twelve (12) years post surgery. Furnas (1982) also reported that massive juvenile hypertrophy of the breast in a 12-year old girl was successfully treated with subcutaneous mastectomy and secondary placement of gel-filled silastic implants. Six years later, no evidence of further residual breast tissue was noted [21]. However, some studies have shown recurrence of the condition after surgery by reduction mammaplasty. Samuelov and Siplovich (1988) reported a case of a 12-year-old girl presenting with juvenile breast hypertrophy who was treated by bilateral reduction mammaplasty with free transplantation of areolae and nipples and removal of $8200 \mathrm{~g}$ of breast tissue. Eleven months later, subcutaneous mastectomy with subpectoral tissue expander insertion was performed due to recurrent breast enlargement with removal of an additional 5000 g. Thus, with young girls, subcutaneous mastectomy with simultaneous or secondary breast implant placement is preferred to prevent any recurrence [22].

In the current study pre-operatively, 23 (67.6\%) reported experiencing headache due to their condition; however, post-operatively, 3 (8.8\%) stated experiencing headache with 2 (5.9\%) and 1 (2.9\%) stating theirs as bad and worse respectively. This headache could also not necessarily be connected to the surgery but rather maybe caused by other disease conditions or even stress or anxiety. Pain/numbness felt in fingers was reported by 28 (82.4\%) before surgery and was totally resolved in all these patients after surgery.
Intertrigo, a condition that occurs in moist area of the skin is usually associated with breast hypertrophy. The size and volume of the breast that lies against the chest wall causes the skin under the breast to fold on each other causing rash and ulceration beneath the breasts. Preoperatively, this condition was reported by 30 (88.2\%); post-operatively the condition had resolved in all the patients.

Persons suffering from breast hypertrophy have always faced the challenge of participating in sports and finding clothes to perfectly fit on them. In the current study, 30 (88.2\%) reported difficulty in participating in sports and finding clothes to fit. However, after surgery, all these persons stated they were able to exercise and participated in any sport and also could easily find clothes to fit them. This is confirmed by Raispis et al. (1995) in their findings; they reported 65\% of patients who had undergone reduction mammaplasty stated they could exercise more after surgery [23].

Pre-operatively, 7 (20.6\%) in this study reported they were unable to breast feed because of the pain they were experiencing. Post-operatively, 18 (52.9\%) reported they were unable to breast feed; these people had all undergone subcutaneous mastectomy hence all breast tissue had been removed and replaced with implants. These persons who underwent subcutaneous mastectomy with simultaneous breast implant placement were in their early teens during time of surgery.

Decreased milk production pre-operatively was experienced by 4 (11.8\%) patients, however, after surgery, the number had increased to 8 (23.5\%) with 6 (17.7\%) stating theirs as bad and 2 (5.9\%) stating theirs as worse. Patients who were made to grade the extent of milk production had all undergone reduction mammaplasty and hence their mammary gland was available for milk production. The results obtained from this study showed that, some patients experienced some degree of complication relating to breastfeeding after reduction mammaplasty. However, Aillet et al. (2002) carried out a study to assess breastfeeding after reduction mammaplasty and concluded that adolescents who underwent reduction mammaplasty could nurse their infants with a complication 
rate similar to that of the normal population [24]. In a similar study to assess the long term results of reduction mammaplasty in teenage girls, Aillet et al. (2001) concluded that breastfeeding was possible after surgery [25].

Before surgery there was no report of reduced nipple sensitivity. However, after surgery, 20 (58.8\%) of the patients stated their nipple sensitivity had reduced with 15 (44.1\%) stating theirs as bad; 3 (8.82\%) stated theirs as worse and 2 (5.88\%) said theirs was worst. Nipple deformation pre-operatively was reported by 29 (85.3\%) patients, but after surgery the number had reduced to 16 (47.1\%); 7 (20.6\%) reported theirs as bad, 4 (11.8\%) and $5(14.7 \%)$ reported theirs as worse and worst respectively. Changes in the nipple sensitivity and nipple deformation may have been caused by the severing of some nerves in this area during the time of surgery.

\subsection{Psychological Complications}

Psychological trauma experienced by persons suffering from breast hypertrophy has been documented by quiet a number of researchers. In this study, all patients, 34 (100.0\%) reported being teased because of their condition, but after surgery, teasing stopped. All the patients reported that before surgery they had a poor image of themselves, but after surgery they had a positive self image and their quality of life had improved since they could now go about their normal duties without developing any ill-feeling such as depression and anxiety. Similarly, Mello et al. (2010) stated in their study that bothself esteem and quality of life significantly improved after breast reduction surgery [26]. Blomqvist et al. (2000) also stated in their finding that reduction mammaplasty resulted in significantly improved quality of life [27]. Thoma et al. (2007) also concluded that patients who underwent breast reduction experienced an improvement in health related quality of life [28].

Satisfaction after breast surgery is an important tool which helps the individual to develop a positive self image. From this study, $85.3 \%$ of the patients reported a high level of satisfaction of their breasts after surgical intervention. Satisfaction was also recorded by Serletti et al. (1992) in their study. They surveyed 109 patients using questionnaires and found out that, majority were pleased with their breast shape and size [29]. Another study was carried out by Makki and Ghanem (1998) to find on the long term results, morbidity and patient satisfaction after reduction mammaplasty. Their survey included 296 patients who underwent reduction mammaplasty between January 1987 and December 1996 and reported $67.6 \%$ satisfaction rate [30].

\section{Conclusion}

Breast surgery provides relief to persons suffering from breast hypertrophy. From the study, it was observed that pre-operative complications associated with this condition were very unbearable. However, after surgical intervention either by reduction mammaplasty or subcutaneous mastectomy the lives of these persons had been improved. Although a few post-operative complications were recorded, the overall satisfaction was excellent. For young adolescents, the preferred surgical procedure to treat breast hypertrophy is by subcutaneous mastectomy with simultaneous or secondary breast implant placement.

\section{REFERENCES}

[1] M. A. Shermak, "Congenital and Developmental Abnormalities of the Breast,” In: I. Jatoi and M. Kaufmann, Eds., Management of Breast Diseases, Springer-Verlag, New York, 2010, pp. 37-49. http://dx.doi.org/10.1007/978-3-540-69743-5 2

[2] E. D. Collins, C. L. Kerrigan, M. Kim, et al., "The Effectiveness of Surgical and Nonsurgical Interventions in Relieving the Symptoms of Macromastia," Plastic and Reconstructive Surgery, Vol. 109, No. 5, 2002, pp. 15561566.

http://dx.doi.org/10.1097/00006534-200204150-00011

[3] E. B. Chadbourne, S. Zhang, M. J. Gordon, et al., "Clinical Outcomes in Reduction Mammaplasty: A Systematic Review and Meta-Analysis of Published Studies,” Mayo Clinic Proceedings, Vol. 76, No. 5, 2001, pp. 503-510. http://dx.doi.org/10.4065/76.5.503

[4] B. J. Miller, S. F. Morris, L. L. Sigurdson, et al., "Prospective Study of Outcomes after Reduction Mammaplasty," Plastic and Reconstructive Surgery, Vol. 115, No. 4, 2005, pp. 1025-1033. http://dx.doi.org/10.1097/01.PRS.0000154212.10845.54

[5] D. Kupfer, D. Dingman and R. Broadbent, "Juvenile Breast Hypertrophy: Report of a Familial Pattern and Review of the Literature," Plastic and Reconstructive Surgery, Vol. 90, No. 2, 1992, pp. 303-309.

[6] B. S. Bauer, K. M. Jones and C. W. Talbot, "Mammary Masses in the Adolescent Female," Surgery of Gynecology and Obstetrics, Vol. 165, No. 1, 1987, pp. 63-65.

[7] C. Templeman and S. P. Hertweck, "Breast Disorders in the Pediatric and Adolescent Patient," Obstetrics and Gynecology Clinics of North America, Vol. 27, No. 1, 2000, pp. 19-34.

http://dx.doi.org/10.1016/S0889-8545(00)80004-2

[8] G. Agaoglu, F. Ozgur and Y. Erk, "Unilateral Virginal Breast Hypertrophy,” Annals of Plastic Surgery, Vol. 45, No. 4, 2000, pp. 451-453. http://dx.doi.org/10.1097/00000637-200045040-00019

[9] J. Govrin-Yehudain, L. Kogan, H. I. Cohen, et al., "Familial Juvenile Hypertrophy of the Breast," Journal of Adolescent Health, Vol. 35, No. 2, 2004, pp. 151-155. http://dx.doi.org/10.1016/j.jadohealth.2003.09.017

[10] M. T. Boschert, C. M. Barone and C. L. Puckett, "Outcome Analysis of Reduction Mammaplasty," Plastic and Reconstructive Surgery, Vol. 98, No. 3, 1996, pp. 451- 
454.

http://dx.doi.org/10.1097/00006534-199609000-00013

[11] K. A. Singh and A. Losken, "Additional Benefits to Reduction Mammaplasty: A Systemic Review of the Literature," Plastic and Reconstructive Surgery, Vol. 129, No. 3, 2012, pp. 562-570. http://dx.doi.org/10.1097/PRS.0b013e31824129ee

[12] B. S. Glatt, D. B. Sarwer, D. E. O’Hara, C. Hamori, L. P. Bucky and D. LaRossa, "A Retrospective Study of Changes in Physical Symptoms and Body Image after Reduction Mammaplasty," Plastic and Reconstructive Surgery, Vol. 103, No. 1, 1999, pp. 76-85. http://dx.doi.org/10.1097/00006534-199901000-00013

[13] D. S. Chang and M. H. McGrath, "Management of Benign Tumors of the Adolescent Breast," Plastic and Reconstructive Surgery, Vol. 120, No. 1, 2007, pp. 13e-19e. http://dx.doi.org/10.1097/01.prs.0000264396.03452.62

[14] A. M. Sadove and J. A. van Aalst, "Congenital and Acquired Pediatric Breast Anomalies: A Review of 20 Years' Experience,” Plastic and Reconstructive Surgery, Vol. 115, No. 4, 2005, pp. 1039-1050. http://dx.doi.org/10.1097/01.PRS.0000154214.99641.72

[15] P. Agbenorku and L. Addae-Mensah, "Management of Juvenile Macromastia: Our Experience at the Komfo Anokye Teaching Hospital (KATH), Kumasi, Ghana,” Indian Journal Clinical Practice, Vol. 2, No. 6, 2001, pp. 13-16.

[16] P. Agbenorku, J. Akpaloo, E. Turkson and M. Agbenorku, "Breast Diseases Including Breast Developmental Anomalies in Kumasi, Ghana," Nigerian Journal of Plastic Surgery, Vol. 3, No. 1, 2007, pp. 11-16. http://dx.doi.org/10.4314/njpsur.v3i1.40386

[17] P. Agbenorku, "Nipple-Areolar Complex (NAC) Composite Grafts in the Management of Macromastia: Review of Complications," Nigerian Journal of Surgical Research, Vol. 8, No. 1, 2006, pp. 77-80.

[18] M. Sabino Neto, M. F. Demattê, M. Freire, E. B. Garcia, M. Quaresma and L. M. Ferreira, "Self-Esteem and Functional Capacity Outcomes Following Reduction Mammaplasty,” Aesthetic Surgery Journal, Vol. 28, No. 4, 2008, pp. 417-420. http://dx.doi.org/10.1016/j.asj.2008.04.006

[19] G. M. Davis, S. L. Ringler, K. Short, D. Sherrick and B. P. Bengtson, "Reduction Mammaplasty: Long-Term Efficacy, Morbidity, and Patient Satisfaction,” Plastic and Reconstructive Surgery, Vol. 96, No. 5, 1995, pp. 11061110. http://dx.doi.org/10.1097/00006534-199510000-00015

[20] Y. Brühlmann and H. Tschopp, "Breast Reduction Improves Symptoms of Macromastia and Has a Long-Lasting Effect,” Annals of Plastic Surgery, Vol. 41, No. 3, 1998, pp. 240-245.

http://dx.doi.org/10.1097/00000637-199809000-00003
[21] D. W. Furnas, "Subcutaneous Mastectomy for Juvenile Hypertrophy of the Breast: Report of a Case," British Journal of Plastic Surgery, Vol. 35, No. 3, 1982, pp. 367370.

[22] R. Samuelov and L. Siplovich, “Juvenile Gigantomastia,” Journal of Pediatric Surgery, Vol. 23, No. 11, 1988, pp. 1014-1015. http://dx.doi.org/10.1016/S0022-3468(88)80010-1

[23] T. Raispis, R. D. Zehring and D. L. Downey, "LongTerm Functional Results after Reduction Mammaplasty,” Annals of Plastic Surgery, Vol. 34, No. 2, 1995, pp. 113116. http://dx.doi.org/10.1097/00000637-199502000-00001

[24] S. Aillet, E. Watier, S. Chevrier, J. P. Pailheret and J. Y. Grall, "Breast Feeding after Reduction Mammaplasty Performed during Adolescence," European Journal of Obstetrics Gynecology and Reproductive Biology, Vol. 101, No. 1, 2002, pp. 79-82. http://dx.doi.org/10.1016/S0301-2115(01)00517-6

[25] S. Aillet, E. Watier, P. Jarno, S. Chevrier and J. P. Pailheret, "Juvenile Breast Hypertrophy: Analysis of LongTerm Results of Reductive Mammaplasty,” Annales De Chirurgie Plastique Esthetique, Vol. 46, No. 6, 2001, pp. 585-594. http://dx.doi.org/10.1016/S0294-1260(01)00064-4

[26] A. A. Mello, N. A. Domingos and M. C. Miyazaki, "Improvement in Quality of Life and Self-Esteem after Breast Reduction Surgery,” Aesthetic Plastic Surgery, Vol. 34, No. 1, 2010, pp. 59-64.

http://dx.doi.org/10.1007/s00266-009-9409-X

[27] L. Blomqvist, A. Eriksson and Y. Brandberg, "Reduction Mammaplasty Provides Long-Term Improvement in Health Status and Quality of Life,” Plastic and Reconstructive Surgery, Vol. 106, No. 5, 2000, pp. 991-997. http://dx.doi.org/10.1097/00006534-200010000-00005

[28] A. Thoma, S. Sprague, K Veltri, E. Duku and W. Furlong, "A Prospective Study of Patients Undergoing Breast Reduction Surgery: Health-Related Quality of Life and Clinical Outcomes,” Plastic and Reconstructive Surgery, Vol. 120, No. 1, 2007, pp. 13-26. http://dx.doi.org/10.1097/01.prs.0000263370.94191.90

[29] J. M. Serletti, G. Reading, E. Caldwell and R. C. Wray, "Long-Term Patient Satisfaction Following Reduction Mammoplasty,” Annals of Plastic Surgery, Vol. 28, No. 4, 1992, pp. 363-365. http://dx.doi.org/10.1097/00000637-199204000-00011

[30] A. Makki and A. Ghanem, "Long-Term Results and Patient Satisfaction with Reduction Mammoplasty,” Annals of Plastic Surgery, Vol. 41, No. 4, 1998, pp. 370-377. http://dx.doi.org/10.1097/00000637-199810000-00004 